\title{
El cuerpo materno del deseo, ese otro origen
}

\author{
The maternal body of desire, \\ that other origin
}

\author{
MARÍA JOSÉ BINETTI \\ IIEGE - UBA - CONICET
}

\begin{abstract}
RESUMEN
El concepto ontológico de «deseo» ha sido elaborado por el dualismo falogocéntrico a partir de las ideas de falta, privación, materia, caída, prohibición o culpa, con la intención de erradicar del cuerpo viviente la energía activa y creadora de lo real, y remitirla a la trascendencia inaccesible del espíritu puro. Habida cuenta del modo en que la diferencia sexual femenina ha sido inscripta por el falogocentrismo hegemónico del lado de la falta, la pasividad, la materia y el mal, el vaciamiento del deseo coincide estrictamente con la eliminación del cuerpo materno y la dominación patriarcal. En tal contexto, el presente artículo se propone restituir el deseo a su potencia de creación en mediación materno-material.
\end{abstract}

PALABRAS CLAVE

FILOSOFÍA FEMINISTA, DIFERENCIA SEXUAL, CAÍDA, MEDIACIÓN, JUEGO.

\begin{abstract}
The ontological concept of «desire» has been elaborated by phallogocentric dualism through the ideas of lack, privation, matter, fall, prohibition or guilt, in order to eradicate the active and creative energy from the living body, and refer it to the inaccessible transcendence of the pure spirit. Insofar as the feminine has been inscribed by the hegemonic phallogocentrism on the side of lack, passivity, matter and evil, the ontological emptying of desire coincides with
\end{abstract}

(C) Contrastes. Revista Internacional de Filosofia, vol. XXIII-N² (2018), pp. 97-113. ISSN: 1136-4076

Departamento de Filosofía, Universidad de Málaga, Facultad de Filosofía y Letras Campus de Teatinos, E-29071 Málaga (España) 
the elimination of maternal body and the patriarchal dominance. In this context, the present article aims to restore desire to its power in maternal-material mediation.

KEY-WORD

FEMINIST PHILOSOPHY, SEXUAL DIFFERENCE, FALL, MEDIATION, PLAYING.

\section{INTRODUCCIÓN}

UNO DE LOS RASGOS DECISIVOS del falogocentrismo hegemónico ha sido la erradicación del deseo - de su origen y dinamismo constitutivo- del cuerpo naciente y su teorización a partir de un dualismo estructural que lo ubica como tensión o tendencia entre el ser pleno y absoluto del cual habría caído, y la carencia, prohibición o culpa que constituye su negatividad. Dicha teorización se articula en 3 ideas centrales: la perfección ideal trascendente, metaforizada en una suerte de paraíso perdido e inalcanzable; el vaciamiento de la materia, interpretada como elemento indeterminado, pasivo y corruptor de la perfección formal; y por último el componente ético-religioso de la prohibición y el pecado, reelaborado psicoanalíticamente como ley, Falo y super-yo.

El común denominador de las diversas teorizaciones falogocéntricas en torno al deseo -filosóficas, religiosas, psicoanalíticas, etc.- reside en la negación que lo determina por oposición dualista a la positividad de una sustancia extrínseca, llámesela objeto, fin, paraíso, Dios, Otro, Otra, de la que se está privado. En el curso de la historia más reciente de la filosofía, dos grandes contragolpes especulativos minaron las bases del falogocentrismo desiderativo, a saber: el monismo dialéctico romántico-idealista y el materialismo vitalista nietzscheano-deleuzeano. El primero superó el dualismo de la privación por la afirmación inmanente de la negatividad; el segundo recuperó la potencia activa de la materia y su primacía como origen y sustrato de toda generación. Sin embargo, ninguno de ellos ha logrado visibilizar la naturaleza sexuada de la metafísica clásica y el sesgo falo-logo-onto-teo-céntrico que, por oposición a la materia-materno-matricial, abortó el dinamismo desiderativo de su seno vital.

En lo que sigue, intentaremos visibilizar los términos en los cuales la diferencia sexual se inscribe en la historia filosófica del deseo, el modo en el que este último ha sido erradicado de la potencia vital y, por restitución simbólica, el sentido del cuerpo materno como origen, medio y resultado del deseo.

\section{EL DESEO EN FALTA DE LA METAFÍSICA FALOGOCÉNTRICA}

El célebre mito referido por el Banquete de Platón sobre el nacimiento de Eros a partir de Poros -el Padre-perfección-y Penía-la madre vaciada-sienta los términos en los cuales la tradición filosófica elaboró durante más de 2000 años el origen del deseo a partir del dualismo de la diferencia sexual. Se llamó 
entonces deseo -eros, $\varepsilon \pi \imath \theta v \mu i ́ \alpha$, cupiditas, apetito- a la tendencia, impulso o principio último de acción de un sujeto sensitivo hacia un objeto que se le presenta como un bien y cuya consecución le produce placer. ${ }^{1}$ En el caso de los vivientes racionales, el impulso sensible debe quedar sujeto a la deliberación intelectual, gracias a la cual apetito se convierte en voluntad libre. ${ }^{2}$

La concepción clásica del deseo supone el sustancialismo metafísico que categoriza clara y distintamente la sustancia-sujeto, la sustancia-objeto, la linealidad intencional que las liga y la causa final como motor primero y elemento principal, todo esto articulado en torno al dualismo que separa y excluye lo actual y lo pasivo, la posesión y la privación, lo positivo y lo negativo, la materia y la forma. En concreto, la materialidad -identificada análogamente con el elemento materno-matricial-constituye el sustrato pasivo, privativo y negativo en el cual decae la perfección inteligible de las formas puras, y su falta es ocasión del deseo como aspiración al Padre-riqueza. Solo hay deseo en los seres hilemórficamente compuestos de forma/perfecta y materia/faltante, y lo hay por la misma imposibilidad estructural que les impide llegar a ser la perfección a la que aspiran.

Las religiones patriarcales y en particular los 3 grandes monoteísmos abrahámicos añadieron a la idea de falta o privación metafísica la perspectiva ético-religiosa de un pecado o culpa original, fruto de la desobediencia al mandato del Padre. Desde el relato de la caída, ${ }^{3}$ el deseo quedó supeditado a una libertad prohibida, maldecida y condenada que debe ser restaurada por el peso de ley, los mandamientos, la obediencia, etc. El deseo se instituye así entre la perfección ideal de un paraíso perdido al cual no se debe volver -cuyo ingreso está custodiado querubines de espada flamígera- y la amenaza de la muerte, el dolor y el castigo.

Que el deseo haya sido originalmente prohibido y caído, es el presupuesto general de la filosofía de la filosofía medieval -explícitamente judeo-cristiana-, la filosofía moderna y el psicoanálisis -implícitamente tales-. Autores como Kant, Schelling o Kierkegaard, para mencionar algún ejemplo, dan por descontada la idea de un mal radical fruto del apetito libre y traducido en la falta ético-metafísica de todo el orden desiderativo. El psicoanálisis, por su parte, convierte el pecado en prohibición, amenaza de castración, falta insuperable y, en última instancia, Thánatos. Se traduce así el dualismo entre el apetito sensibles y el racional en los términos de Instinkt: comportamiento genéticamente fijado, y Trieb o pulsión: fuerza abierta a la indeterminación del objeto o fin y por lo tanto relativamente variable, imprevisible e intervenida por experiencia

1 Cf. Aristóteles, Acerca del alma. Madrid: Gredos, 1978, II, 3, 414b 6.

2 Cf. Ibid., III, 10-11, 433 a ss.

3 Cf. Gén., 2, 16-17. 
histórica del sujeto. ${ }^{4}$ En cualquiera de los casos, se trata de la tendencia hacia un objeto o fin más o menos determinado.

El mito fundacional del Padre psicoanalítico ${ }^{5}$ sobre el tabú del incesto, la prohibición, la amenaza de castración y culpa persecutoria por la transgresión a la Ley reditan el relato bíblico en clave superyoica. El deseo psíquico comienza así en el Falo que impone la separación materna, produce la conciencia del yo e introduce en el universo proactivo de la realidad y la cultura. Tal como resulta del complejo de Edipo, lo materno equivaldría a aquel paraíso de omnipotencia y perfección ideal irremediablemente perdido, o mejor, construido como pérdida por la prohibición y el tabú. Asimismo, el complejo de Edipo transpone la sexualidad adulta a la relación objetal con la madre, convirtiendo a ésta última en objeto sexual prohibido por el dueño de la sexualidad materna, vale decir, por el Falo.

Según el pansexualismo freudiano del primer Freud, el cuerpo materno constituye el objeto libidinal primario de un estado de indefensión e invalidez absoluta que la madre viene a paliar. ${ }^{6}$ La fantasía de la omnipotencia materna emerge por simetría dualista con ese estado de negatividad radical y su paraíso resulta finalmente perdido gracias a la Ley del Padre, con la cual comienza el principio de realidad, orden, productividad. La resolución del complejo de Edipo consiste en la constitución del super-yo por la idealización de lo imaginariamente perdido y la internalización de la prohibición, es decir, por la represión de la energía pulsional erradicada del ámbito de la conciencia y sus construcciones simbólicas.

En el caso del último Freud, la introducción teórica de la pulsión de muerte ${ }^{7}$ radicaliza el dualismo bajo la primacía de la destructividad y la disolución final de la vida en la inorganicidad de la materia, asumiendo que tal es la condición última de la vida. La acción negativa de la muerte replica a lo largo de toda la vida como odio, agresión, compulsión a repetir lo displacentero, etc., porque tal sería la condición originaria de la psiquis. Winnicott interpretó con lucidez «el concepto de pulsión de muerte podría ser descrito como una reafirmación del principio de pecado original», ${ }^{8}$ es decir, como la traducción psíquica de lo negativo dispuesto en el origen y fin último del deseo.

$4 C f$. J. Laplanche, y J.-B. Pontalis, Diccionario de psicoanálisis. Barcelona: Labor, 1981, pp. 198, 324-327, 374-75.

5 Cf. S. Freud, Totem y tabú, en Obras Completas. Buenos Aires: Amorrortu, 1999, vol. XIII.

$6 C f$. T. Geyskens y P. Van Haute, From Death Instinct to Attachment Theory. The Primacy of the Child in Freud, Klein, and Hermann, Other Press, New York 2007, pp. x ss.

7 Cf. S. Freud, Más allá del principio del placer, en op. cit., vol. XVIII.

8 D. W. Winnicott, Playing and reality. London \& New York: Routledge, 2005, p. 95 . 
La primacía de la muerte como pulsión original es recogida a su modo por el psicoanálisis de Melanie Klein, Sándor Ferenczi, Otto Rank y Jacques Lacan en la idea de un trauma o falta del cual todo procede, en particular el deseo. Según Melanie Klein, ${ }^{9}$ en el origen es el trauma, la indefensión radical y la angustia de una muerte segura, de lo cual deriva la primera relación objetal con el pecho materno como recurso paliativo ante la destructividad, la ansiedad persecutoria y la indefensión. El deseo, primariamente materno, constituye entonces una relación secundaria, derivada de la pulsión de muerte y la catástrofe traumática del nacimiento.

Autores como Sándor Ferenczi ${ }^{10} \mathrm{u}$ Otto Rank ${ }^{11}$ han sido contundentes a la hora de describir la condición primaria del psiquismo humano en los términos psicopatológicos de trauma y catástrofe, como si el nacimiento significase una suerte de expulsión Edénica, caída y condenación. La oceánica Thalassa matricial está irremediablemente perdida y la Ley del Padre posee el valor salvacional de quebrar la fijación materna y transferir la libido hacia el mundo real y la cultura. Klein, Ferenczi o Rank coinciden en el fantasma de una madre omnipotente proyectado desde la indefensión absoluta del naciente humano y finalmente vencida por el Padre, con el cual comienza la realidad verdadera, esto es, el dualismo todo/nada, muerte/vida, naturaleza/cultura.

El caso de Lacan merece particular atención en la medida en que su lingüisticismo basal, herencia post-estructuralista, exige tanto la pérdida del cuerpo materno como la configuración del deseo a partir de un significante vacío -el Falo- que solo se significa a sí mismo, esto es, que se significa como imposibilidad metafísica de acceso a lo real trascendente. ${ }^{12}$ El dualismo lacaniano distingue claramente la pulsión -de naturaleza materna-material-y el deseo, de naturaleza fálica por estar articulado en torno a un significante siempre en falta. El deseo corresponde al orden metafórico de una palabra dispuesta en el lugar del significante, es decir, de la falta, la imposibilidad y trascendencia edénica de lo real. Entre la pulsión sensible y el deseo parlante no hay para Lacan continuidad esencial sino Alteridad radical.

En palabras del autor, el Otro totalmente Otro es «el lugar de causa del deseo», ${ }^{13}$ remotamente causado por el paraíso perdido. El Falo, el Otro son el nombre lacaniano de la muerte como negatividad última. El destino del deseo es así el mismo que su origen: la caída, la imposibilidad, la nostalgia y el barra-

9 Cf. M. Klein, Envidia y gratitud. Barcelona: Paidós, 1988.

$10 C f$. S. Ferenczi, Thalassa. A Theory of Genitality. New York: W.W. Norton \& Company, 1968, pp. 56 ss.

11 Cf. O. Rank, El trauma del nacimiento. Buenos Aires: Paidós, 1961.

12 Remitimos a J. Lacan, «La significación del falo», en Escritos 2. México: Siglo XXI, 1987, pp. 653-662.

13 Cf. Ibid., p. 659. 
miento de lo que nunca será. El dualismo lacaniano desplaza el deseo del Otro a la trascendencia de un residuo real inaccesible, una suerte de Edén perdido del lingüisticismo, en cuya falta se constituye el universo significante. Judith Butler comenta al respecto que «para Lacan, el deseo está siempre vinculado al proyecto de una recuperación imposible», ${ }^{14}$ su destino es narrar siempre la misma historia de un amor infeliz, que paga el precio del pecado original con la condena del exilio.

El pensamiento feminista de la diferencia sexual ha sido contundente a la hora de denunciar la expulsión materno-material del deseo y su deambular siempre en falta y en culpa. Podríamos resumir la crítica deconstructiva de este feminismo en 3 ideas centrales: la erradicación del deseo de su matriz vital; el dualismo materia-espíritu, naturaleza-cultura, instinto-lenguaje, etc.; y la erección del mundo ideal -Padre, prohibición, super-yo- como metafísica moralizante de la energía desiderativa. Luce Irigaray lo abrevia en estos términos: "se ingresa al deseo cuando se ingresa a la relación con el padre. ¡Esto es dramático!» ${ }^{15}$ y ha sido en efecto el mayor drama de la existencia: el de un padre incapaz de concebir y parir la pulsión vital, pero muy capaz de separar y prohibir lo que el ser ha unido. La cultura hegemónica ha instalado durante milenios una suerte de fetichismo de la prohibición que sueña con engendrar, pero cuyos únicos engendros son la represión de la vida y el opio de la trascendencia ideal.

Christina Wieland ${ }^{16}$ comenta al respecto que el complejo de Edipo, lejos de lograr la separación de la madre real, alimenta la fantasía de una madre omnipresente, la culpa persecutoria, los impulsos destructivos y la represión de la energía desiderativa, que continuamente retorna como síntoma de una cultura mortalmente enferma. Malestar, descontento, angustia, agresión, fenómenos masoquistas y auto-destructivos, etc., son los síntomas de una civilización arrancada de su propio cuerpo y desconectada de sus fuerzas vitales. No sólo psicoanalistas feministas como Luce Irigaray, Christina Wieland o Jessica Benjamin, sino también teóricos del apego como Imre Harmann o Donald Woods Winnicott han diagnosticado el origen de la enfermedad en una «demanda cultural por la cual el apego es eliminado de su curso natural en el ser humano». ${ }^{17}$ Las raíces psico-patológicas de la cultura residen en desapego

14 J. Butler, Subjects of Desire. Hegelian Reflections in Twentieth-Century France. New York: Columbia University Press, 1987, p. 193.

15 L. Irigaray, Le corps-à-corps avec la mere. Montreal: Les editions de la pleine lune, 1981, p. 89

16 C. Wieland, The Undead Mother. Psychoanalytic Explorations of Masculinity, Femininity and Matricide. London: Karnac Books, 2002, pp. 14, 27.

17 T. Geyskens y P. Van Haute, op. cit., p. 132. 
prematuro, inconsolable, insuperable y traumático tanto a nivel subjetivo como colectivo y cultural.

Una vez arrancado de su propio cuerpo, el deseo fue entregado a la simbólica viril que lo instituye siempre en falta, caída y culpa. Viceversa, la cultura fue arrancada de su energía vital y entregada a la superioridad racional, tramadora de discursos y redes de poder. Que el deseo sea hijo de la ley, el poder y el discurso es verdad, pero la verdad del Padre, instalada sobre el dualismo naturaleza-cultura, vida-razón, animalidad-humanidad, instinto-pulsión, con el fin de la hegemonía masculina sobre el cuerpo materno.

El malestar más profundo de la subjetividad y la civilización humana reside en ese dualismo insuperable que ha arrancado a la humanidad de sus instintos, al deseo de su propio cuerpo y a la palabra de su pulso vital. Pero lo bueno del caso es que donde se origina la enfermedad, reside la curación.

\section{EL OTRO ORIGEN DEL DESEO: UN CUERPO MEDIAL}

La-otra-concepción del deseo parte de los siguientes presupuestos ontológicos: la inmanencia materialista de lo real, el desdoblamiento dinámico de lo uno, la continuidad medial de la diferencia y la acción recíproca de la vida en todas sus formas de potenciación. Para deslindar equívocos, empezaremos por afirmar que se trata de una concepción no dualista, que impide la interpretación de la negatividad material como privación, falta o degeneración de una perfección sustancial. material como reificación sustancialista del no-ser, la privación o pasividad degenerativa de la perfección ideal. Se trata más bien de una doble negación desdoblada en su propia diferencia auto-activa. Desde el punto de vista de la mítica fundacional, esto significa que no hay paraíso perdido en la trascendencia ideal, ni catástrofe del nacimiento, ni caída en falta. En el mismo sentido, el cuerpo materno no es objeto primario de la invalidez humana, ni sujeto devorador, ni omnipotencia prohibida. Fuera de todo dualismo, nos referiremos en lo que sigue a un deseo concebido en la mediación de su propio cuerpo.

Si el deseo falogocéntrico significa, sucintamente dicho, la tendencia a un objeto que falta o la descarga de lo que sobra, el deseo del que hablamos aquí es el nombre vivo y material de la mediación, es decir, el desdoblamiento de la identidad en sus propias posibilidades de creación, de lo que simplemente es en lo que puede llegar a ser, el devenir de lo uno en lo otro. El concepto del deseo como mediación fue sistematizado por Hegel como corolario de un desarrollo especulativo que comprende al idealismo en general. Cuando Hegel asegura que el medio es superior al fin y que «nada hay en el cielo, en la naturaleza, en el espíritu o donde sea, que no contenga la inmediación y la mediación, así 
que estas dos determinaciones se presentan como unidas e inseparables», ${ }^{18}$ sienta las bases de una nueva negatividad ya no simplemente privativa sino activamente creadora. En una versión más contemporánea de esta misma posición especulativa, Gilles Deleuze y Félix Guattari aseguran que el devenir sólo tiene solo tiene medio ${ }^{19}$ y el medio habilita todo devenir. La primacía circular y cíclica del medio sobre la linealidad del fin, supera el dualismo de la trascendencia objetiva por la inmanencia de una subjetividad reduplicada.

La Filosofía del espíritu ${ }^{20}$ constituye un hito en la conceptualización ontológica del deseo - begierde-. Aunque no desconocemos el sesgo espiritualista y androcéntrico hacia el cual se desliza el tratamiento hegeliano, ${ }^{21}$ los límites de estas páginas solo nos permiten focalizar los términos mediales en los cuales Hegel inscribe el deseo como potencia en sí y para sí, movimiento autorreflexivo cuyo devenir desdobla la inmediatez de lo dado en lo que puede llegar a ser. El deseo desdobla la identidad, la diferencia, para resolverla finalmente en sí misma como otra. Tal devenir inmanente determina la esencia de la vida en general y de la autoconciencia en particular, ambas desdobladas en su propia diferencia subjetivo-objetiva, activo-pasiva, positivo-negativa, y recuperadas en su propia diferencia.

Dicho en otros términos, el deseo expresa un modo de ser relacional, donde lo real no es la cosa en-sí del sustancialismo abstracto dispuesta hacia otra cosa en-sí, sino la relación inmanente consigo mismo como otro y con lo otro como sí mismo. Bien dice Judith Butler que para Hegel «el deseo es una tácita persecución de la identidad», ${ }^{22}$ con la precisión de que se trata aquí de una identidad relacional, siempre en mediación y auto-diferenciación. La alteridad es constitutiva de una identidad descentrada y abierta, y esto puede leerse en dos sentidos: como alteridad de lo deseado, o como la inflexión del desear en el ser deseado por otro. En el primer caso, el otro deseado deviene

18 G. W. F. Hegel, Ciencia de la Lógica. Trad. A. y R. Mondolfo, Buenos Aires: Solar - Hachette, 1968, p. 64.

$19 C f$. G. Deleuze y F. Guattari, Mil mesetas. Capitalismo y esquizofrenia. Trad. José Vázquez Pérez, Pre-textos, Valencia 2002, p. 304.

$20 C f$. G. W. F. Hegel, Fenomenología del espiritu. Trad. W. Roces, México, México: Fondo de Cultura Económica, 1966, pp. 108 ss.

21 A título introductorio, recordemos que el tratamiento del deseo seguido por la Fenomenología del espíritu hegeliana se desliza hacia la dialéctica del trabajo como apropiación destructiva del objeto material, y la lucha a muerte por el deseo de reconocimiento. Cualquier de estos puntos, de amplia difusión marxista, se basan en el supuesto falogocéntrico de un estado de guerra natural y en un modelo de trabajo industrializado, que invisibilizan por completo la relación matricial como célula política y la creación vital como paradigma de trabajo. Dejamos para un próximo artículo el análisis de esta cuestión.

22 J. Butler, op. cit., p. 9. 
sí-mismo; en el segundo caso, el sí-mismo deviene deseado por otro. El mutuo reconocimiento consuma para Hegel la construcción del deseo como medio de la alteridad y su concepción original se encuentra, para el feminismo de la diferencia, en el cuerpo materno: matriz de todo descentramiento, desdoblamiento absoluto en unidad radical, pura acción recíproca materno-filial. En el origen del deseo es la mediación materno-material como categoría ontológica de un devenir siempre otro.

En y por el cuerpo materno, el deseo construye su propia alteridad, ese desdoblamiento en el cual se reconoce a sí mismo por el reconocimiento del otro. Tal como el cuerpo materno la expone y significa, la dialéctica del deseo reside antes que en la destrucción del otro y la lucha a muerte -ese falogocentrismo insuperable del pensamiento moderno y contemporáneo al cual no podemos referirnos con mayor detalle en este espacio-más bien en la creación de la alteridad y la lucha a vida. El cuerpo materno expresa la dialéctica de un deseo capaz dar vida a la diferencia absoluta y de recuperarse a sí mismo en su alteridad. Recíprocamente, él expresa la dialéctica de recibir la vida en la relación más radical, aquella por el cual el ser se inscribirá para siempre como dinamismo relacional, pura reciprocidad, deseo absoluto.

En otras palabras, el cuerpo materno expresa la condición ontológica del ser como relación, mediación, deseo. Él no debe ser sustancialistamente entendido como el cuerpo de una madre reificada o idealizada, ni del hijx como sujeto apropiador del objeto-madre. Por el contrario, el cuerpo materno significa estrictamente el cuerpo del deseo, el espacio de su desdoblamiento y recuperación, el dinamismo de su auto-diferenciación. La mediación que el cuerpo materno concibe, es recíprocamente deseo del otro y alteridad creadora de sí mismo. Por eso, su negatividad es inmanente a la acción productiva, vale decir, determinación positiva.

Cuando la mediación del deseo es reinterpretada en términos maternomateriales -en lugar de su clásica interpretación androcéntrica en términos de lucha a muerte, apropiación, trabajo industrial y destrucción de la materia-, el resultado es la creación del otro por la propia negatividad reflexiva. Lo negativo no juega aquí como falta, privación o muerte de un otro sustancial, sino como reflexión ontológica del sí mismo que abre el espacio inmanente de la alteridad. Tal es el sentido en el que Deleuze y Guattari afirman que el deseo «no implica ninguna carencia, ninguna imposibilidad, y tampoco se mide con el placer»». ${ }^{23}$ Por el contrario, una vez superada la linealidad causal del objeto trascendente, el deseo se mide con la circularidad inmanente de su auto-diferencia, en-otro y para-otro, que denominamos aquí cuerpo materno. En y por el cuerpo materno, el deseo crea la alteridad como reflexión o mediación

23 G. Deleuze y F. Guattari, op. cit., p. 160.

Contrastes vol. XXIII-N² (2018) 
de sí mismo, supera el ego-centrismo y construye el dinamismo relacional del ser como inter- e intra-actualidad.

La propia negación reflexiva -en lugar de la destrucción del otro exteriorsostiene la alteridad matricialmente deseada y reconocida, y en esta reflexión reside en rigor la infinitud del movimiento desiderativo, capaz de crearse a sí mismo su propia alteridad. El deseo es un devenir infinito, o bien, un automovimiento desplegado en la inmanencia de su propia alteridad. Su origen no es más otro que el de esta infinitud continuamente desdoblada y esto significa que en el origen del deseo no hay ningún paraíso perdido, ninguna caída dualista en el mundo de la finitud, ni degeneración material alguna. Lo que propiamente hay en el cielo, en la tierra y en cuerpo materno es la mediación matricial por la cual lo que era uno deviene dos y su diferencia resulta siempre tres. El cuerpo materno es ese 3 reduplicado: ni 1 ni 2 , sino estricta mediación.

Así como hay una - otra-concepción filosófica del deseo, también hay una -otra-concepción psicoanalítica del mismo que ubica su origen en el cuerpo materno. Nos referimos en concreto a la así llamada «teoría del apego» de autores como Imre Herman, John Bolwby, Donald Woods Winnicott o Rene Spitz, entre otros. El «apego» mencionado alude en rigor a la pulsión de agarre, aferramiento, abrazo o aprehensión de la madre que caracteriza al mamífero recién nacido, en particular primates y humanos. A partir de lo que venimos diciendo, podríamos concebir ontológicamente el apego como la expresión psíquica de la mediación, es decir, como el desdoblamiento inmanente de un deseo infinito continuamente aferrado a la finitud como a su propia alteridad. El apego a lo finito comienza y termina en el cuerpo materno, y cuando no hay cuerpo al que aferrarse, lo que queda del deseo es la angustia, el trauma, la destrucción, el Falo, el Gran Otro. Haber arrancado el deseo del abrazo finito para eyectarlo a las abstracciones del mundo ideal constituye la perversión radical de la cultura falogocéntrica, comentada líneas atrás.

Por el contrario, la teoría del apego se caracteriza por abandonar el marco dualista del psicoanálisis clásico y asumir en su lugar una suerte de monismo psíquico, fundado en el apego materno como pulsión básica e irreductible. Fuera del dualismo, el cuerpo materno del apego no es el objeto primario del deseo, sino la relación constitutiva del mismo, su diferencia y mediación. Él no es tampoco el paraíso perdido del gran drama del nacimiento, sino lo que hace «necesario postular un nacimiento normal no traumático», ${ }^{24}$ porque 10 traumático no es nacer, sino caer del Edén. Menos que nada, el cuerpo materno del apego no significa esa omnipotencia fantasmal que viene a satisfacer la carencia o indefensión radical, sino más bien el medio que separa y une, diferencia y abraza a la vez.

24 D. W. Winnicott, Human Nature. New York: Schocken Books, 1988, p. 143. 
Por otra parte, el apego no se define ni por el instinto de autoconservación, como si la madre prestara un recurso de salvataje frente a la invalidez absoluta; ni por la pulsión sexual, relativamente indeterminada y por lo tanto susceptible de satisfacerse con cualquier objeto; ni por la pulsión de muerte, esa oceánica nada que lo disuelve todo. En cualquiera de estos casos, el apego dependería de un fundamento causal precedente, en lugar de constituirse como origen psíquico irreductible del cual deriva todo lo demás. En efecto, fenómenos negativos tales como la angustia, la agresión, la destrucción, etc., son comprendidos por los teóricos del apego a partir de la frustración o inhibición de su fuerza basal.

El apego constituye un «estado de ser» ${ }^{25} \mathrm{y}$, específicamente, el modo de ser originario: relacional y medial. Su dinamismo articula la identidad psíquica en el medio de la alteridad como síntesis diferenciada subjetivo/objetiva, activo/ pasiva, interior/exterior, biológica/espiritual, natural/cultural, etc. La acción del apego es recíproca: ni del uno ni del otro sino de lo tercero como unidad medial. En un intento por evitar el dualismo naturaleza-cultura, John Bowlby califica el apego como una «conducta instintiva» ${ }^{26}$ que sin perder su codificación genética abarca sin embargo múltiples posibilidades de comportamiento, influidas por el medio. En un sentido similar, Imre Hermann considera al apego como la fuente pulsional que moviliza y alimenta todo el aparato psíquico, compuesta tanto por un patrón neuro-biológico como por la influencia variable de la experiencia y la cultura.

El análisis de Hermann se refiere concretamente al «instinto filial» ${ }^{27}$ de mamíferos, primates y humanos como primer principio del dinamismo psíquico. El instinto filial o instinto de cramponnement-como la traducción francesa de Hermann lo denomina- indica la aprehensión del cuerpo materno como «unidad redoblada en mutua completitud», ${ }^{28}$ esto es, por mediación. Incluso el nido o el huevo comparten análogamente para Hermann la morfología matricial del origen y el dinamismo medial de una esfera que Peter Sloterdijk denomina dúplice y una a la vez. ${ }^{29}$ Vida intrauterina, abrazo filial, pecho nutricio, apego o cramponnement, todos comparten la energía de un deseo que es en cualquier caso unidad reduplicada: concepción de identidad la alteridad en y por la diferencia. Tal es para Hermann la condición tipo del instinto, a saber, la archi-unidad materno-filial ${ }^{30}$ del cuerpo vivo.

25 T. Geyskens y P. Van Haute, op. cit., pp. 92-93.

26 J. Bowlby, Attachment and Loss. New York: Basic Books, 1982, vol. 1, p. 37 ss.

27 Cf. I. Hermann, L'instinct filial. Trad. G. Kassai, Paris: Denoël, 1972.

28 Cf. I. Hermann, op. cit., p. 102.

29 Cf. P. Sloterdijk, Esferas I. Burbujas. Microesferología. Trad. Isidoro Reguera, Madrid: Siruela, 2003.

30 I. Hermann, op. cit., p. 53. 
Jamás ha existido, ni intra-útero ni extra-útero, la omnipotencia pura, una y simple de las fantasmagorías falogocéntricas. Lo que el cuerpo materno enseña en todo caso, tiempo y lugar, es la mediación de lo uno, el desdoblamiento, lo tercero matricial. Él es recíprocamente diferencia y unidad, parición y apego, separación y relación. Arrancado de su cuerpo, el deseo devino prohibición, inhibición de la potencia vital, síntomas de inseguridad, dependencia, infantilismo, angustia, agresión, etc. Tal es lo que sucede de manera sistemática en la cultura patriarcal, donde el instinto filial es prematuramente abortado a fin de subsidiar, asegura Herman, la estructura familiar, ${ }^{31}$ esto es, a fin de convertir el cuerpo materno del deseo en propiedad patriarcal.

El desapego de la energía vital, del deseo, la desconexión del cuerpo materno está en la matriz de una enfermedad cultural cuyo origen ha quedado sepultado en los cimientos de la ideología falogocéntrica. El agudo diagnóstico y la cura radical que el pensamiento feminista aporta, conduce a rehabilitar la aprehensión esencial de la vida y reabrir a través suyo esos espacios mediales de in-existencia donde la díada medial repite su unidad original. Esto conduce a una nueva concepción cultural, dispuesta en continuidad esencial con el cuerpo materno. En lo que sigue, veremos cómo ese gran discípulo de Hermann que fue Donald Winnicott contribuyó a sacar las últimas conclusiones de un instinto matricial elevado al superior dinamismo de la cultura universal.

\section{LA CULTURA: ESA EXPANSIÓN LÚDICA DEL CUERPO MATERNO}

Cuando el cuerpo materno es asumido como origen, medio y resultado del deseo, entonces la negatividad, la muerte y la diferencia quedan eo ipso integradas al dinamismo de la vida como instancias dialécticas de su propio desdoblamiento creador. El dualismo del deseo-en-falta, fruto de una cultura arrancada de su matriz corporal y tramada en los significantes del poder falogocéntrico, es así superado por la inmanencia monista de un deseo medial, capaz de reponer la cultura en continuidad esencial con su propio cuerpo como desdoblamiento creador del mismo.

La concepción del deseo fuera del dualismo inconcebible de la falta convierte su negatividad medial en estado permanente de gestación, parición, creación vital. Mientras que el deseo-falta destruye y lucha a muerte, el deseomedio crea y lucha a vida. El propio cuerpo materno es resultado recíproco de esa acción fecunda, cuya única necesidad es su infinitud creadora. Con este tipo de acción se asocian los conceptos de espontaneidad, libertad y juego en alusión a un obrar que solo depende de su dinamismo inmanente. Y tal es el cuerpo materno, entregado al juego libre de su propia creación material y simbólica, natural y cultural.

31 I. Hermann, op. cit., p. 102.

Contrastes vol. XXIII-N² (2018) 
Como decíamos líneas atrás, el cuerpo materno no es sustancia individual -ni de la madre ni del hijx- sino relación constitutiva de su diferencia en la unidad recíproca que el deseo media. El nacimiento del otro irrumpe como deseo y su mediación abre un espacio relacional que erradica el solipsismo de la individualidad abstracta e instituye su identidad intra- e inter-subjetiva como ser sí mismo en y por otro. En ese espacio relacional que es el cuerpo materno, el deseo crea, juega y expande vida. El primer juego creador, el originario y arquetípico, acontece en el cuerpo materno y lo hace no solo en términos ontológicos sin también físicos, psíquicos y culturales. La humanidad juega, antes que todo y sobre todo, con la madre, para jugar luego con todo lo demás.

La poética mistraliana dice esto mismo en los siguientes términos, que vale la pena citar in extenso por la intensidad materna-material de su lengua:

Tú a veces me comprabas, y otras me hacías, los juguetes: una muñeca de ojos muy grandes, como los míos; una casita que se desbarataba a poca costa... Pero los juguetes muertos yo no los amaba, tú te acuerdas; el más lindo era para mí tu propio cuerpo. Jugaba con tus cabellos como con hilitos de agua escurridizos; con tu barbilla redonda; con tus dedos que trenzaba y destrenzaba. Tu rostro inclinado era para tu hija todo el espectáculo del mundo. Con curiosidad miraba tu parpadear rápido y el juego de la luz que se hacía desde dentro de tus ojos verdes, y aquello tan extraño que solía pasar sobre tu cara cuando tenías una cosa que yo ignoraba, cuando eras desgraciada, madre. Sí; todito mi mundo era tu semblante: tu frente como un llano con rastrojo dorado; tus mejillas como la loma, y los surcos que la pena cavaba hacia los extremos de la boca, eran dos pequeños vallecitos tiernos. Aprendí los colores y las formas mirando tu cabeza: el color de la última tarde estaba en tu cabellera; el temblor de las hierbecitas, en tus pestañas, y el tallo de las plantas, en tu cuello, que al doblarse hacia mí hacía un pliegue lleno de intimidad. Y cuando ya supe caminar de la mano tuya, apegadita a ti cual si fuera un pliegue grande de tu falda, salí a conocer tu valle y mi valle dulcísimo. ${ }^{32}$

Antes de que Winnicott se preguntara dónde es el juego, ${ }^{33}$ Mistral le había respondido: en el cuerpo materno. El niñx juega con la madre y si la madre no está, convierte su falta en creación de mundo, apego de finitud, invención de cultura. La humanidad aprehende el mundo en el cuerpo materno y cuando puede caminar por sí sola, se abraza al cuerpo materno del mundo.

Tal desplazamiento de la relación primaria a nuevas relaciones o expansiones vitales es lo que Winnicott ha denominado fenómenos, espacios u objetos

32 G. Mistral, «Evocación de la madre», en Páginas en prosa. Buenos Aires: Kapelusz, 1962, p. 40.

$33 C f$. D. W. Winnicott, Playing and reality..., cit. 
«transicionales» o «potenciales». Los fenómenos transicionales o potenciales no son en rigor ni objetos ni sujetos, ni interiores ni exteriores, ni fantasías ni realidades, sino estrictamente hablando «un área intermedia de experiencia» ${ }^{34}$ realizada en la síntesis dialéctica del sí mismo en el otro. Los fenómenos transicionales son el nombre que la psicología evolutiva de Winnicott le da a la mediación: acción transitiva y recíproca de la diferencia en identidad matricial. Así como el cuerpo materno no es un objeto, tampoco su espacio es una cosa sustancial sino un dinamismo de pasaje que abre la identidad al intra-juego de la diferencia y la creación.

En el juego, el deseo se realiza como libertad, espontaneidad, inmanencia auto-activa de un cuerpo en continua mediación; por él, la subjetividad se crea a sí misma deviniendo alteridad. Y lo relevante del caso es esto solo acontece en el cuerpo materno: cuando la mediación de otra mirada y otra palabra abren el espacio relacional, cuando la mano del apego presta confianza y seguridad al paso. Solo en esa apertura medial, el niño se aprehende a sí mismo en y por otra. En palabras de Winnicott, «el niño está solo únicamente en presencia de alguien», ${ }^{35}$ por esa suerte de desdoblamiento desiderativo que lo trae de vuelta hacia sí mismo. Solo entonces, explica Jessica Benjamin, en la seguridad del cuerpo materno, el niño se relaja y «su impulso deviene su propio deseo». ${ }^{36} \mathrm{El}$ espacio potencial resulta así efectivamente potenciador porque en él es posible hacer real la diferencia, la creación, lo nuevo.

Falogocéntricamente, se ha interpretado la apertura al mundo de la autoconciencia y la creación cultural como el salto dualista de la naturaleza material, bruta y muda, a la luminosidad racional, parlante y trabajadora. Entre la una y la otra, lo que hay es falta, prohibición, Falo, represión y, en el mejor de los casos, sublimación de un fin objetal a otro. Sin embargo, lo cierto es que el cuerpo materno del deseo sugiere otra concepción medial de la autoconciencia y la cultura, establecidas por continuidad y repetición del origen. Con esta otra concepción coincide el feminismo de la diferencia, la lengua materna de Mistral $\mathrm{y}$, en términos de apego, el psicoanálisis de Winnicott o incluso Hermann. Para cualquiera de ellos, la creación cultural sigue el patrón lúdico abierto por la relación matricial. Ese cuerpo materno que comienza siendo semblante, mejillas y cabellera de la madre, recogerá luego la alteridad del valle, la hierba, la tarde, y lo hará por su propia potencialidad creadora. Hermann explica a Mistral asegurando que «la unidad dual madre-niño se transpone a formas duales

34 Ibid., p. 3.

35 Ibid., p. 130.

36 J. Benjamin, A Desire of One's Own: Psychoanalytic Feminism and Intersubjective Space. Wisconsin-Milwaukee: Center for Twentieth Century Studies, 1985, pp. 16-17. 
de pensar» ${ }^{37}$ en permanente expansión vital. La transposición simbólica del cuerpo materno opera para Hermann algo así como una des-materialización, ritualización y recreación, concebida -añadimos nosotras- por la propia negatividad medial del cuerpo materno.

El pensamiento de Winnicott resulta contundente respecto de 3 ideas indisociables, a saber: el nacimiento de la cultura por la expansión inmanente del espacio transicional; la esencia lúdica y por lo tanto, desiderativa y libre de la acción cultural; y la universalidad del juego como concepción subjetivoobjetiva del sí mismo en otro. Cualquiera de estas ideas reconduce al cuerpo materno como origen, medio y resultado de toda creación. También el universo cultural nace «como desarrollo del espacio transicional» o «fenómeno transicional derivado $»^{38}$ de la relación matricial, y lo hace en juego con sus propias posibilidades de expansión. «El juego es universal» ${ }^{39}$ porque en sus playas se crea la vida.

Si la perversión, la violencia y el instinto de muerte falogocéntricos abortaron la cultura del cuerpo materno, la primacía universal del juego recupera la continuidad matricial de la infancia como su condición de existencia, sentido y logos del ser material. Fuera de todo dualismo, el universo cultural nace de un mismo deseo cuyo cuerpo anhela darse a luz una y otra vez en la infinitud de su vitalidad siempre nueva, siempre recién parida y aprehendida de finitud.

\section{EN CONCLUSIÓN, EL DESEO SUPONE UNA ONTOLOGÍA SEXUADA}

A excepción de su pervivencia en el imaginario patriarcal, el paraíso perdido del deseo nunca existió; tampoco su caída y menos que nada su culpa siempre en falta. Por el contrario, lo que ha existido en todo tiempo y lugar, dentro y fuera del seno materno, es la mediación, la relación, la unidad diferenciada de un sí mismo concebido en y por otro. Si bien la superación especulativa del dualismo metafísico acometida por la modernidad idealista hizo posible la comprensión del deseo en términos mediales, sin embargo ha sido necesaria una nueva superación materno-material del espiritualismo falogocéntrico a fin de consumar la conceptualización desiderativa en términos de concepción y nacimiento. Este último es el intento del feminismo de la diferencia retomado en estas páginas.

Cuando el cuerpo materno es afirmado como origen inmanente, medio y resultado del deseo, su pulsión se desplaza hacia una nueva lógica vital y cultural capaz de concebir el ser en términos de continuidad relacional y recíproca. El cuerpo del deseo es energía infinita -porque solo lo infinito es capaz de

37 I. Hermann, op. cit., p. 400.

38 D. W. Winnicott, Playing and reality..., cit., pp. xiii-xiv.

39 Ibid., p. 56. 
concebirse en su propia mediación- siempre apegada a la finitud -porque solo lo finito constituye su medio--. Esa virtualidad infinita que satura y regenera todos los límites es lo que Luce Irigaray aproxima a la locura como continente oscuro del deseo. ${ }^{40}$ En el cuerpo materno, el deseo restituye su locura, su infinitud, su báquico delirio, su goce creador; en él recobra también sus pies danzantes, su invitación al juego, su inocencia inmaculada.

Por el contrario, un deseo sin cuerpo materno es una naturaleza en lucha a muerte, un trabajo productivo de destrucción y apropiación, un significante sin referente material, un cultura enferma, prematura y desapegada. Huelga insistir, aunque nunca huelga lo bastante, en que la construcción falogocéntrica del deseo de espaldas al cuerpo materno y de cara a la caída, la prohibición, la falta, la castración etc., tuvo por fin la eliminación de las mujeres de la producción activa de cultura; su reducción a un sustrato material pasivo y degenerante; y la apropiación de su energía vital. Incluso la fálica madre omnipotente está al servicio de eliminar la realidad materna: esa que concibe, alimenta y pare en la diferencia, así como abraza, mira y apega en la identidad; la madre medial del cuerpo-en/por-cuerpo deseante.

Restituir el verdadero origen del deseo significa restituir, por acción recíproca, el verdadero deseo del origen, que no yace en el Edén perdido, ni en la inorganicidad de la materia bruta y muda, ni el Gran Otro trascedente, sino mucho más acá, en el eterno renacimiento de la vida. Vivir y querer vivir, afirmar, potenciar y fecundar la vida son ese cuerpo materno en acción deseante. Lo que Susan Griffin le reclama a su madre, lo reclama el deseo de su origen, el origen de su deseo, la cultura de su juego, la mujer de su poder creador, la razón de su instinto, el devenir de su infancia, el filósofo de su niñx:

\author{
Madre \\ escribo a casa \\ estoy sola \\ devuélveme mi cuerpo. ${ }^{41}$
}

María José BinetTi es doctora en Filosofía por la Universidad de Navarra (2004) e investigadora adjunta del CONICET (Argentina). Desde el 2015 desarrolla su actividad en el Instituto Interdisciplinarios de Estudios de Género de la Universidad de Buenos Aires. Su trabajo de

40 L. Irigaray, op. cit., p. 14.

41 Citado por A. Rich en Nacemos de mujer. La maternidad como experiencia e institución. Trad. Ana Becciu, Madrid: Cátedra, 1996, p. 317. 
investigación se ha focalizado sobre el pensamiento de Søren Kierkegaard en el contexto del idealismo alemán y el pensamiento francés contemporáneo.

Línea actual de investigación

filosofía feminista de la diferencia sexual y la reconstrucción de la «matricialidad» como categoría filosófica.

Publicaciones recientes:

El idealismo de Kierkegaard (Universidad Iberoamericana, México 2015);

«Gabriela Mistral, en lengua materna-material-matricial», en Lectora: revista de dones $i$ textualitat, Universitat de Barcelona, 23 (2017), pp. 117-131;

«La inocencia del origen. Continuum materno, parto y libertad», en Journal of Philosophical Criticism, 1/1 (2018), pp. 3-28. https://osf.io/a4xzs/

Dirección postal

Rivadavia 1082

Luján - CP. 6700

Buenos Aires

Argentina

Email: mjbinetti@gmail.com 
